IEEE IECON Industrial Electronics Conference, pp. 594-600, Dallas Texas USA, Oct. 2014.

http://ieeexplore.ieee.org/xpl/abstractKeywords.jsp?arnumber=7048561

ISBN: 978-1-4799-4032-5

ISSN: $1553-572 \mathrm{X}$

DOI: $10.1109 /$ IECON.2014.7048561

This material is posted here with permission of the IEEE. Such permission of the IEEE does not in any way imply IEEE endorsement of any of Group of Energy and Power Electronics, University of Minho, products or services. Internal or personal use of this material is permitted. However, permission to reprint/republish this material for advertising or promotional purposes or for creating new collective works for resale or redistribution must be obtained from the IEEE by writing to pubs-permissions@ieee.org. By choosing to view this document, you agree to all provisions of the copyright laws protecting it.

(C) 2014 IEEE 


\title{
FPGA Field Oriented Control of an Axial Flux Motor-in-Wheel
}

\author{
Delfim Pedrosa, Hugo Peixoto, Henrique Gonçalves, Júlio S. Martins, Carlos Couto, João L. Afonso \\ ALGORITMI Research Centre - University of Minho \\ Guimarães, Portugal \\ \{delfim.pedrosa | hugo.peixoto | henrique.goncalves | julio.martins | carlos.couto | joao.l.afonso \}@ algoritmi.uminho.pt
}

\begin{abstract}
This paper presents the design and the prototype implementation of a three-phase power inverter developed to drive a motor-in-wheel. The control system is implemented in a FPGA (Field Programmable Gate Array) device. The paper describes the Field Oriented Control (FOC) algorithm and the Space Vector Modulation (SVM) technique that were implemented. The control platform uses a Spartan-3E FPGA board, programmed with Verilog language. Simulation and experimental results are presented to validate the developed system operation under different load conditions. Finally are presented conclusions based on the experimental results.
\end{abstract}

Keywords-Axial Flux Motor-in-Wheel; Field Oriented Control (FOC); Field Programmable Gate Array (FPGA); Space Vector Modulation (SVM)

\section{INTRODUCTION}

It is estimated that within 50 years the oil resources are virtually exhausted. While it is also expected that the overall number of vehicles will increase from 700 million to 2.5 billion, as consequence of the world population increase. Therefore, alternative energy sources and storage systems are needed. Electric mobility is growing as response to this need of reducing vehicles' dependence on fossil fuels [1], [2].

Electric motors manufacturers are sensible to this change of the mobility paradigm, and new motors, specially designed for electric vehicles (EVs) are being developed. The axial flux motors are one of the most promising technologies due to its high power density. They can be mounted inside the vehicle's wheels, reducing, or even eliminating mechanical components. This concept is known as motor-in-wheel.

Electric motors can be used in electric vehicles to drive the vehicle, or in hybrid electric vehicles to assist the internal combustion engine (ICE). When assisting the ICE, the electric motor only produces the peak power required by the vehicle, reducing the ICE power, and consequently reducing fuel consumption, and therefore improving vehicle's efficiency. Another advantage of using electric motors in the powertrain is its ability to work as motor or generator. This characteristic allows regenerative braking, that increases the efficiency and autonomy of the vehicle.

This paper presents the power converter and the control algorithms design, simulation and experimental results of a motor-in-wheel controller. The proposed solution uses Field Oriented Control (FOC), and a Space Vector Modulation (SVM) techniques. The control platform uses a Spartan-3E FPGA Starter Kit Board from Xilinx.

\section{FIELD ORIENTED CONTROL}

With the Field Oriented Control (FOC) the motor torque and magnetization flux are, directly and separately, controlled. Using the FOC the motor is controlled as it is a DC motor, with all the arising advantages, namely instantaneous torque and flux control, which improves the motor performance both in transient and steady state operation [3]-[5].

Fig. 1 depicts the FOC with a Space Vector Modulation (SVM) technique. The Clarke transform is used to represent the motor currents in a two axes orthogonal $\alpha-\beta$ coordinate system. These currents are called $i_{\alpha}$ and $i_{\beta}$. With the Park transform the $\alpha-\beta$ components are translated to a two axes orthogonal $d-q$ coordinate system synchronous with the rotor position. In this system the motor currents are called $I_{d}$ and $I_{q}$ Each of these current components is then compared with the correspondent reference current, $I_{d}{ }^{*}$ (flux reference) and $I_{q}{ }^{*}$ (torque reference). The $I_{d}{ }^{*}$ reference is set to zero in order to be obtained the maximum torque. The $I_{q}{ }^{*}$ reference is generated by the speed regulator. Using two PI controllers the $d-q$ axis motor reference voltages $\left(V_{d}\right.$ and $\left.V_{q}\right)$ are obtained. The inverse Park transform translates the voltage references in two $\alpha-\beta$ reference voltage components, $v_{\alpha}$ and $v_{\beta}$, which are used as inputs for the SVM technique.

The motor was modeled using the $d-q$ axis mathematical model. So, the main equations of the motor are expressed under a $d-q$ coordinate system, as shown in equations (1) to (4). It was assumed that the rotor flux is constant and the motor losses were neglected [6], [7].

$$
\begin{gathered}
v_{q}=R_{s} i_{q}+L_{q} \frac{d i_{q}}{d t}+\omega_{e}\left(\phi_{m}+L_{d} i_{d}\right) \\
v_{d}=R_{s} i_{d}+L_{d} \frac{d i_{d}}{d t}-\omega_{e}\left(L_{q} i_{q}\right) \\
\omega_{e}=\frac{p}{2} \omega \\
T_{e}=\left(\frac{3}{2}\right)\left(\frac{p}{2}\right)\left(i_{q} \phi_{m}+\left(L_{d}-L_{q}\right) i_{q} i_{d}\right)
\end{gathered}
$$

Where, $v_{d}$ and $v_{q}$, are the stator voltages, $i_{d}$ and $i_{q}$ are the stator currents, $L_{d}$ and $L_{q}$ are the motor inductances, $R_{s}$ is the stator resistance, $\omega_{e}$ is the electrical rotor speed, $\omega$ is the rotor angular speed, $\phi_{m}$ is the rotor permanent magnets flux, and $p$ is the number of poles. 


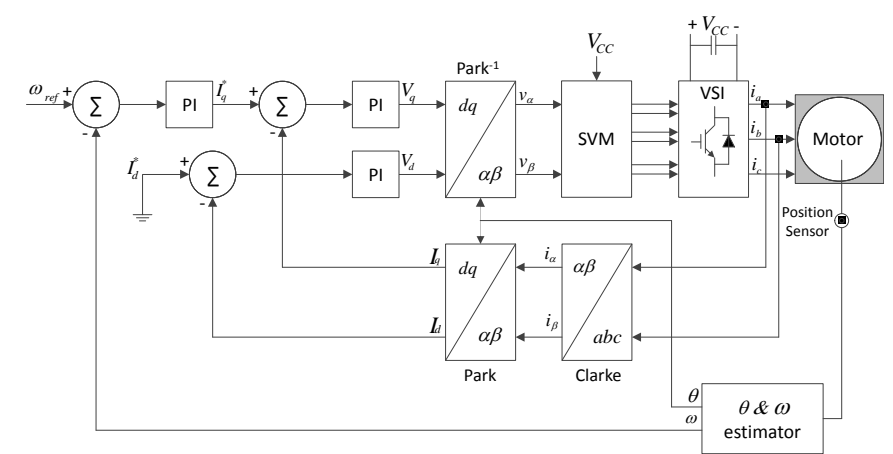

Fig. 1. Field Oriented Control (FOC) block diagram.

\section{Space Vector Modulation}

As it can be seen in Fig. 1 the FOC produces two $\alpha-\beta$ reference voltage components, $v_{\alpha}$ and $v_{\beta}$, which represent the voltages that should be applied to the motor. The translation of these reference voltages in gate pulses for the inverter semiconductors is done by a pulse width modulation technique. Since the reference voltage is a vector, and considering the advantages of the Space Vector Modulation (SVM) technique, it was the natural choice. In comparison with other modulation techniques, SVM does a more efficient use of the DC-link voltage, generates voltages with lower total harmonic distortion and reduces the power semiconductors switching losses, improving efficiency [8], [9]. The SVM has good performance in applications where it is necessary a variable frequency, as it is the case of motors control. Nevertheless, it should be mentioned that it consumes more computational resources [8].

The working principle of the SVM is depicted in Fig. 2. It consists in representing the reference voltage $\left(V_{\text {ref }}\right)$ in a $\alpha-\beta$ coordinate system, that is divided in eight different sectors defined by the voltage vectors, $V_{0}$ to $V_{7}$ [8].

The procedure to obtain the modulation duty cycles can be divided into three steps [10]:

\section{1) Determination of the Sector of $V_{\text {ref }}$}

With equations (5) and (6), and Table I, is identified the sector where vector $V_{\text {ref }}$ is placed.

$$
\left\{\begin{array}{lll}
\text { If } v_{\beta}>0 & \text { Then } A=1, & \text { Else } A=0 \\
\text { If }\left(v_{\alpha} \sqrt{3}-v_{\beta}\right)>0 & \text { Then } B=1, & \text { Else } B=0 \\
\text { If }\left(-v_{\alpha} \sqrt{3}-v_{\beta}\right)>0 & \text { Then } C=1, & \text { Else } C=0
\end{array}\right.
$$

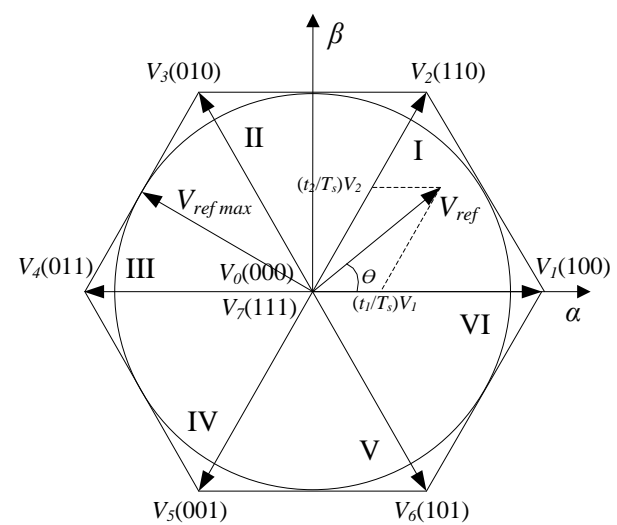

Fig. 2. SVM sectors and voltage reference $\left(V_{\text {ref }}\right)$ in the $\alpha-\beta$ coordinate system.
TABLE I. $\quad V_{R E F}$ SECTORS

\begin{tabular}{|c|c|c|c|c|c|c|}
\hline $\mathbf{N}$ & 1 & 2 & 3 & 4 & 5 & 6 \\
\hline Sector & II & VI & I & IV & III & V \\
\hline
\end{tabular}

$$
N=A+2 B+4 C
$$

\section{2) Calculation of the Dwell Times $t 1$ and $t 2$}

With equations (7) to (9) the auxiliary variables $X, Y$ and $Z$ are calculated. These auxiliary variables are used to define the dwell times, $t_{1}$ and $t_{2}$, according to Table II.

$$
\begin{gathered}
X=\frac{\sqrt{3} u_{\beta}}{V_{C C}} T_{s} \\
Y=\frac{1}{2 \mathrm{~V}_{\mathrm{CC}}}\left(\sqrt{3} u_{\beta}+3 u_{\alpha}\right) T_{s} \\
Z=\frac{1}{2 V_{C C}}\left(\sqrt{3} u_{\beta}-3 u_{\alpha}\right) T_{s}
\end{gathered}
$$

Where, $V_{c c}$ is the DC-link voltage and $T_{s}$ is the switching period.

\section{3) Determination of the Duty Cycles $T_{a}, T_{b}$ and $T_{c}$}

The next equations show the calculation of the duty cycles. Table III organizes the duty cycles according to $V_{\text {ref }}$ sector.

$$
\begin{gathered}
t_{a O N}=\frac{\left(T_{s}-t_{1}-t_{2}\right)}{4} \\
t_{b O N}=t_{a O N}+\frac{t_{1}}{2} \\
t_{c O N}=t_{b O N}+\frac{t_{2}}{2}
\end{gathered}
$$

\section{Simulation RESUlTS}

Before implementing the system a set of simulations were performed, in order to assess the system behavior and to improve design specifications. The simulation software used was PSIM 9.1 from Powersimtech.

Many times electric motors manufactures do not provide all the parameters needed for its proper simulation Therefore, a set of experimental tests are needed in order to obtain them [11]. Table IV presents the main parameters of the motor-in-wheel that was used.

\section{A. No-Load Simulations}

Fig. 4 shows the motor speed along the time and its reference when the motor is operating without any mechanical load. It is

TABLE II. DWELL TIMES OF THE SWITCHING STATE VECTORS

\begin{tabular}{|c|c|c|c|c|c|c|}
\hline Sector & I & II & III & IV & V & VI \\
\hline $\boldsymbol{t}_{\mathbf{1}}$ & $-Z$ & $Z$ & $X$ & $-X$ & $-Y$ & $Y$ \\
\hline $\boldsymbol{t}_{\mathbf{2}}$ & $X$ & $Y$ & $-Y$ & $Z$ & $-Z$ & $-X$ \\
\hline
\end{tabular}

TABLE III. DUTY CYCLES FOR EACH SECTOR

\begin{tabular}{|c|c|c|c|c|c|c|}
\hline Sector & I & II & III & IV & V & VI \\
\hline $\boldsymbol{T}_{\boldsymbol{a}}$ & $t_{a O N}$ & $t_{b O N}$ & $t_{c O N}$ & $t_{c O N}$ & $t_{b O N}$ & $t_{a O N}$ \\
\hline $\boldsymbol{T}_{\boldsymbol{b}}$ & $t_{b O N}$ & $t_{a O N}$ & $t_{a O N}$ & $t_{b O N}$ & $t_{c O N}$ & $t_{c O N}$ \\
\hline $\boldsymbol{T}_{\boldsymbol{c}}$ & $t_{c O N}$ & $t_{c O N}$ & $t_{b O N}$ & $t_{a O N}$ & $t_{a O N}$ & $t_{b O N}$ \\
\hline
\end{tabular}


TABLE IV. MOTOR-IN-WHELl CHARACTERISTICS

\begin{tabular}{|c|c|c|}
\hline Characteristic & Value & Unit \\
\hline Nominal Power & 1.8 & $\mathrm{~kW}$ \\
\hline Speed & 520 & $\mathrm{rpm}$ \\
\hline Nominal Voltage & 33.2 & $\mathrm{~V}$ \\
\hline Nominal Current & 40.8 & $\mathrm{~A}$ \\
\hline Torque & 33 & $\mathrm{Nm}$ \\
\hline Number of Poles & 32 & - \\
\hline Nominal Frequency & 139 & $\mathrm{~Hz}$ \\
\hline Stator Resistance & 58 & $\mathrm{~m} \Omega$ \\
\hline$d$-axis Stator Inductance & 205 & $\mu \mathrm{H}$ \\
\hline$q$-axis Stator Inductance & 221 & $\mu \mathrm{H}$ \\
\hline Voltage constant & 86.8 & $\mathrm{~V} / 1000 \mathrm{rpm}$ \\
\hline
\end{tabular}

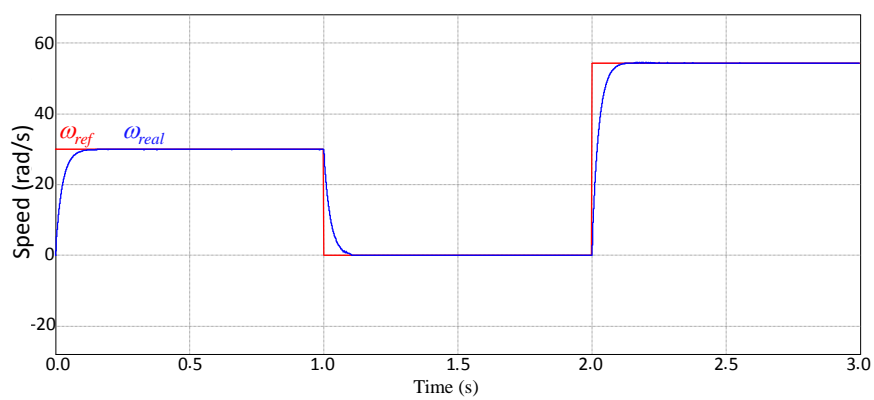

Fig. 4. Motor speed $\left(\omega_{\text {real }}\right)$ and its reference $\left(\omega_{\text {ref }}\right)$ without mechanical load.

possible to observe the speed following the reference. It is also visible that the system has a fast response to reference variations.

In Fig. 3 is shown the motor voltages $\left(v_{a}, v_{b}\right.$ and $\left.v_{c}\right)$ and currents $\left(i_{a}, i_{b}\right.$ and $\left.i_{c}\right)$ at nominal speed without mechanical load. The voltages were measured between each motor phase and the middle point of the DC-link, it was also used a low-pass filter set with a $500 \mathrm{~Hz}$ cutoff frequency.

(a)

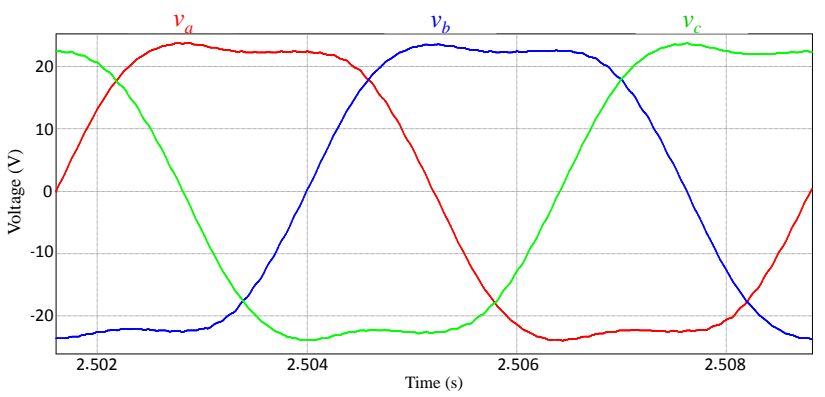

(b)

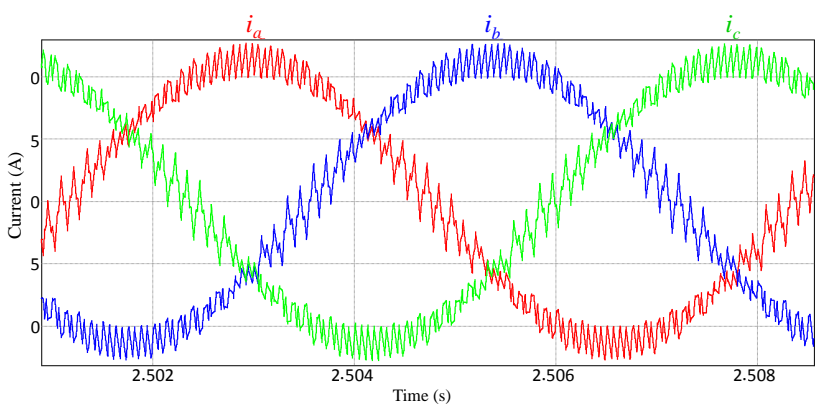

Fig. 3. Voltages and currents of the motor without nominal mechanical load: (a) $v_{a}, v_{b}$ and $v_{c}$; (b) $i_{a}, i_{b}$ and $i_{c}$.

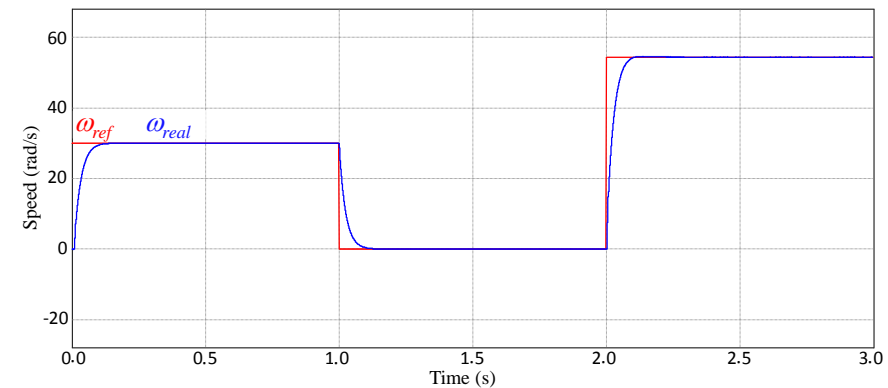

Fig. 5. Motor speed $\left(\omega_{\text {real }}\right)$ and its reference $\left(\omega_{\text {ref }}\right)$ with nominal mechanical load.

\section{B. Full-Load Simulations}

The system was simulated with a mechanical load of $33 \mathrm{Nm}$. Fig. 5 shows the motor speed and its reference when the motor runs at nominal load. It is possible to observe the speed following its reference. It is also visible that the system has a fast response to reference variations, and that it has not changed with the load.

Fig. 6 shows the motor voltages $\left(v_{a}, v_{b}, v_{c}, v_{a b}, v_{b c}\right.$ and $\left.v_{c a}\right)$ and currents $\left(i_{a}, i_{b}\right.$ and $\left.i_{c}\right)$ at nominal speed. Like in the no-load simulations, $v_{a}, v_{b}$, and $v_{c}$ voltages were obtained between the motor phase and the middle point of the DC-link, while $v_{a b}, v_{b c}$, and $v_{c a}$ voltages are the phase-to-phase motor voltages. It is

(a)

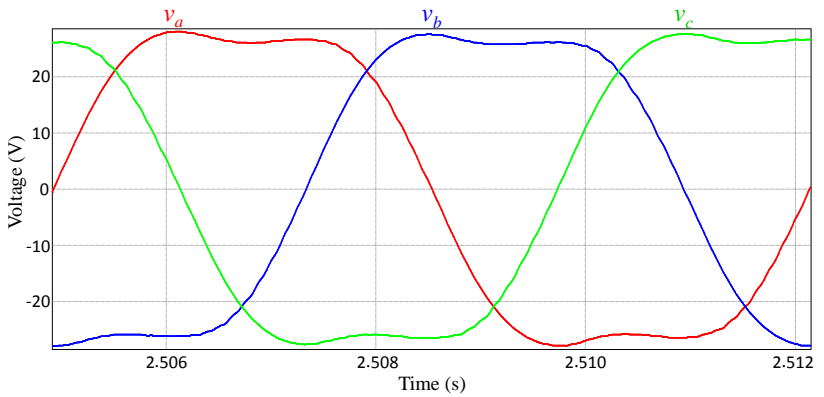

(b)

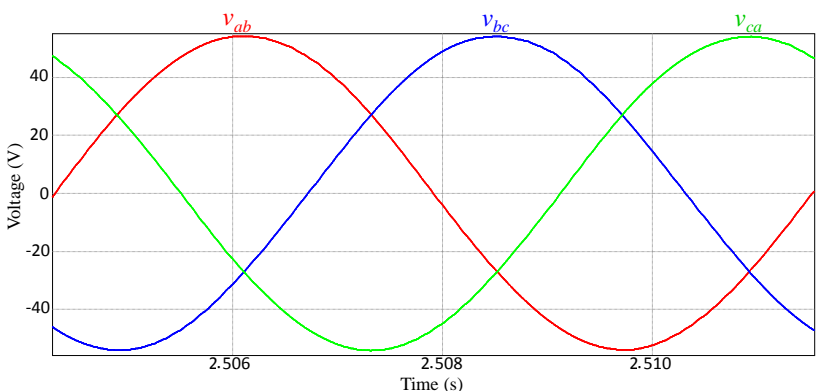

(c)

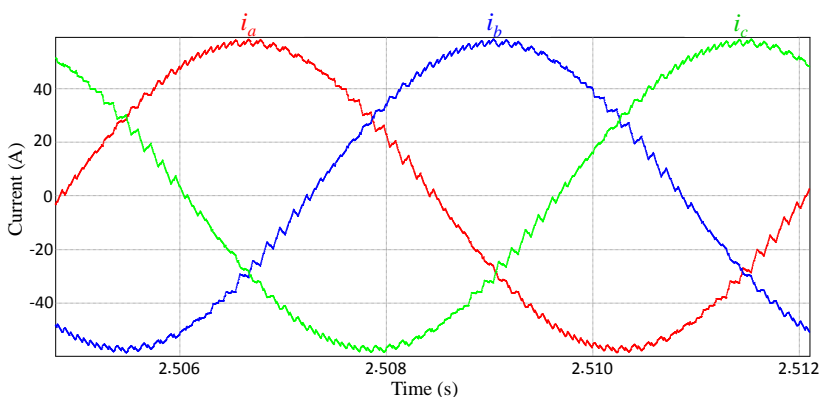

Fig. 6. Voltages and currents of the motor at nominal speed and with nominal mechanical load: (a) $v_{a}, v_{b}$ and $v_{c}$; (b) $v_{a b}, v_{b c}$ and $v_{c a}$; (c) $i_{a}, i_{b}$ and $i_{c}$. 
visible that the currents ripple is lower than with no-load operation, due to the higher RMS currents values.

\section{SYSTEM IMPLEMENTATION}

As shown in Fig. 7, it was developed a three-phase power inverter to drive the motor. This inverter is composed by three IGBT legs, and three driver boards from SEMIKRON.

The control platform uses the FPGA Spartan-3E Starter Kit Board from Xilinx (Fig. 8).

This board uses the Xilinx XC3S1600E Spartan-3E with 232 I/O ports and around 10000 logic cells. This board also has other features such as: a $50 \mathrm{MHz}$ oscillator, a $16 \mathrm{Mb}$ flash memory with SPI communication, two RS-232 ports, and support for a LCD [12]. The code was programmed in Verilog language to be achieved a faster system response.

The FOC process implementation follows the state machine presented in Fig. 9. In each state sequentially or parallel tasks can coexist. The sequence and parallelization of the tasks

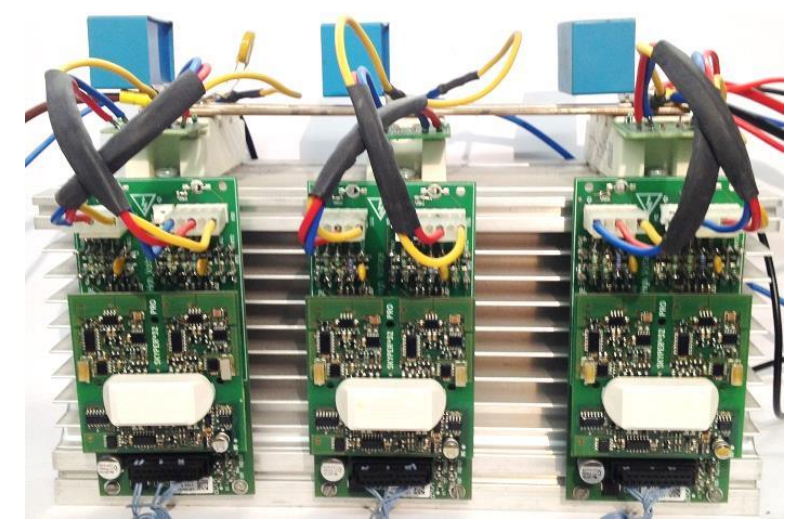

Fig. 7. Developed three-phase power inverter.

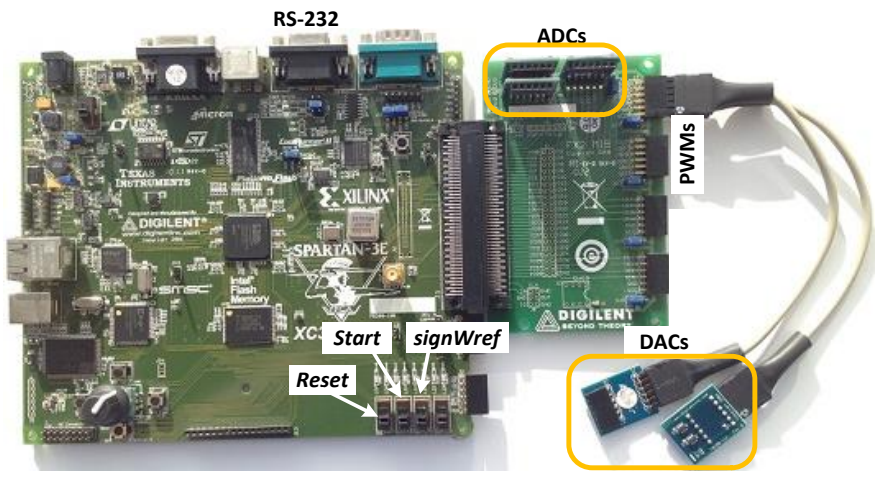

Fig. 8. Spartan-3E FPGA Starter Kit Board.

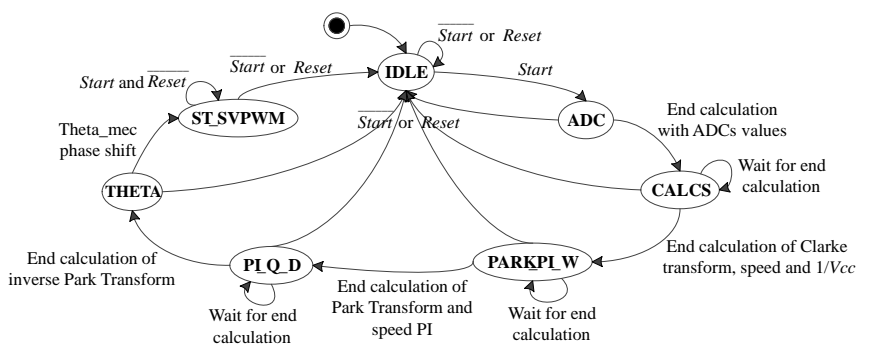

Fig. 9. The FOC state machine. execution are shown in Fig. 10. The transaction between two different states takes one clock cycle.

The signal conditioning between the voltage and current sensors from the inverter, accelerator position, rotor position, and the FPGA is done by the board presented in Fig. 11 (a). The inverter command signals are adjusted by the board shown in Fig. 11 (b).

\section{EXPERIMENTAL RESULTS}

The experimental results were obtained with the support of the test bench shown in Fig. 12. With this test bench is possible to change the mechanical load between 0 and $47 \mathrm{Nm}$ [13].

\section{A. Experimental No-Load Test}

In Fig. 13 are shown the motor speed and its reference with no-load condition. It is visible that the motor speed follows the reference. It is also visible that the system has a fast response to reference variations.

In Fig. 14 are shown the motor voltages $\left(v_{a b}, v_{b c}\right.$ and $\left.v_{c a}\right)$ and currents $\left(i_{a}, i_{b}\right.$ and $\left.i_{c}\right)$ at an angular speed of $44 \mathrm{rad} / \mathrm{s}$. The voltages were acquired with an oscilloscope and a low-pass filter set with a $500 \mathrm{~Hz}$ cutoff frequency. The currents were measured using FLUKE i400s current probes set with a scale of $10 \mathrm{mV} / \mathrm{A}$.

\section{B. Experimental Load Test}

In Fig. 15 are shown the motor speed and its reference with different mechanical loads. Five different time instants are depicted. At instant $T_{1}$, the mechanical load was changed from 0 to $10 \mathrm{Nm}$ and the motor speed reference was set to $31 \mathrm{rad} / \mathrm{s}$, resulting in a speed overshoot of about $4.5 \mathrm{rad} / \mathrm{s}$, during $0.5 \mathrm{~s}$. At instant $T_{2}$, the mechanical load is increased by $15 \mathrm{Nm}$. As

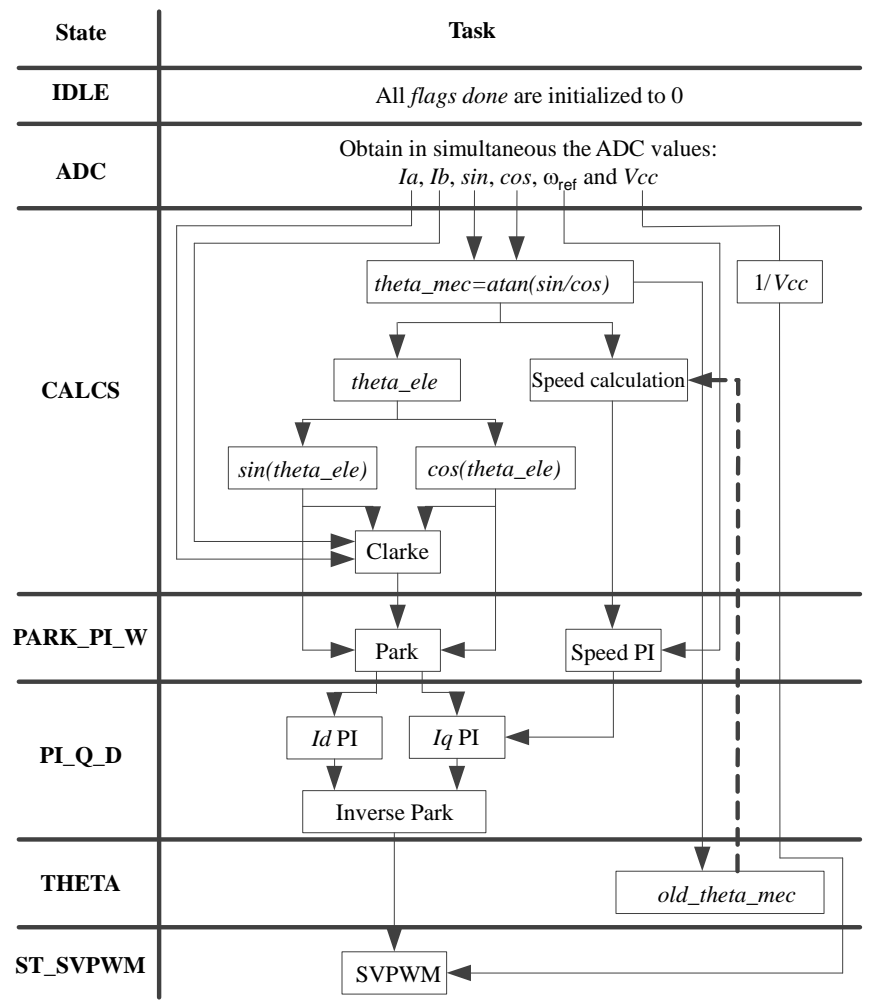

Fig. 10. The FOC state machine. 
(a)

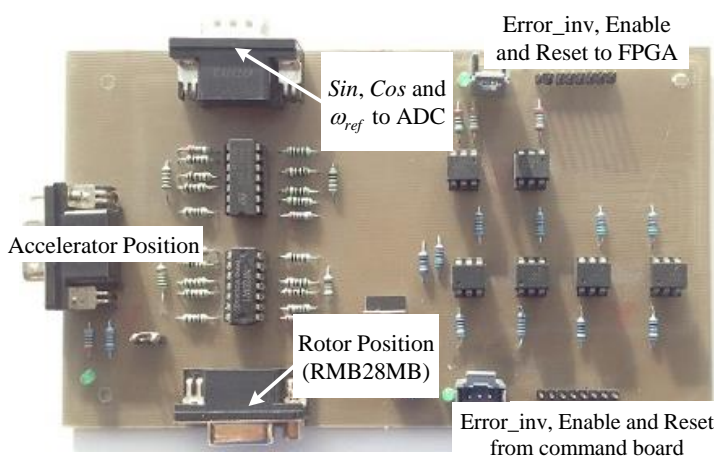

(b)

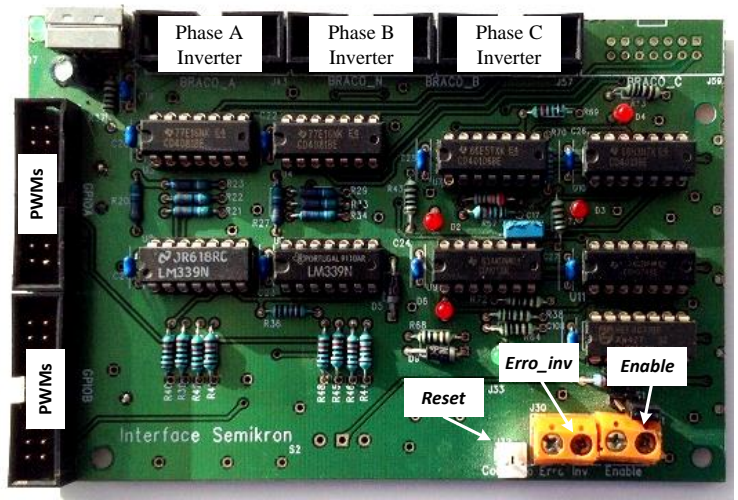

Fig. 11. Developed FPGA signal conditioning boards: (a) Input signals; (b) Inverter command signals.

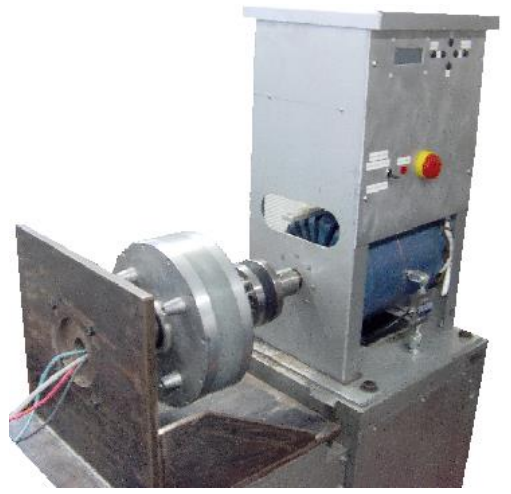

Fig. 12. Assemblage between the motor-in-wheel and the test bench.

consequence the speed slightly decreases, to increase again to the reference values $1 \mathrm{~s}$ later. At instant $T_{3}$, the mechanical load is decreased by $15 \mathrm{Nm}$, returning to the initial value. Consequently, the speed slightly increases, about $1 \mathrm{~s}$ later decreases to the reference value. At instant $T_{4}$, the speed reference starts decreasing to zero. Finally, at instant $T_{5}$, it was given a reference for the motor to stop.

In Fig. 16 are shown the motor voltages $\left(v_{a b}, v_{b c}\right.$ and $\left.v_{c a}\right)$ and currents $\left(i_{a}, i_{b}\right.$ and $\left.i_{c}\right)$ at $33 \mathrm{rad} / \mathrm{s}$ with nominal mechanical load. Like in the no-load test, the voltages and currents were also obtained with an oscilloscope and current probes.

\section{CONCLUSIONS}

In this paper was presented a three-phase power inverter developed to drive an Axial Flux Motor-in-Wheel. It was also presented the simulation and experimental results obtained with a control system using Field Oriented Control (FOC) and Space

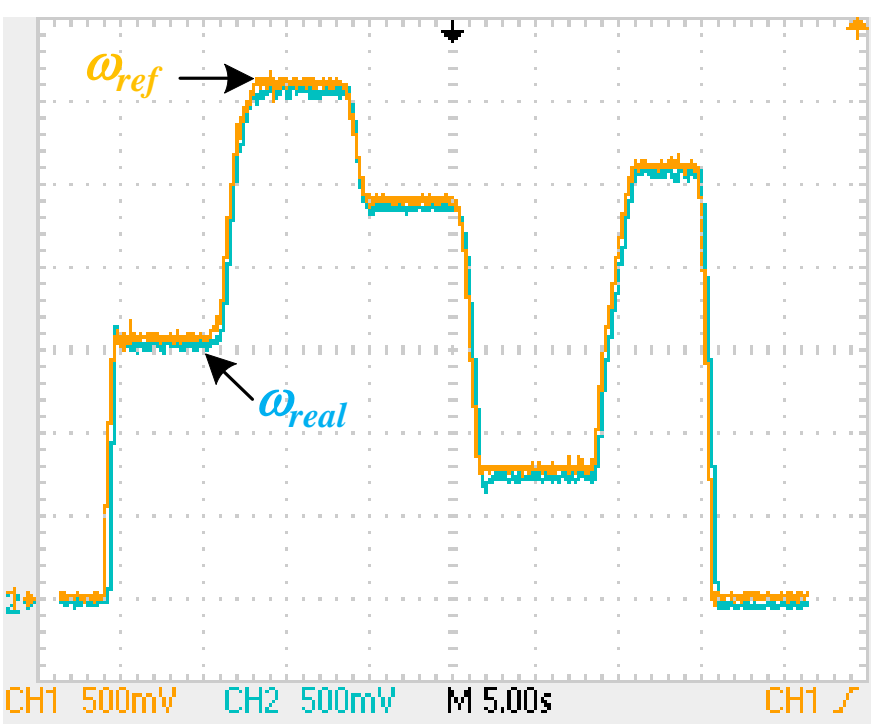

Fig. 13. No-load motor speed $\left(\omega_{\text {real }}-8 \mathrm{rad} / \mathrm{s} / \mathrm{div}\right)$ and its reference $\left(\omega_{\text {ref }}-8 \mathrm{rad} / \mathrm{s} / \mathrm{div}\right)$.

(a)

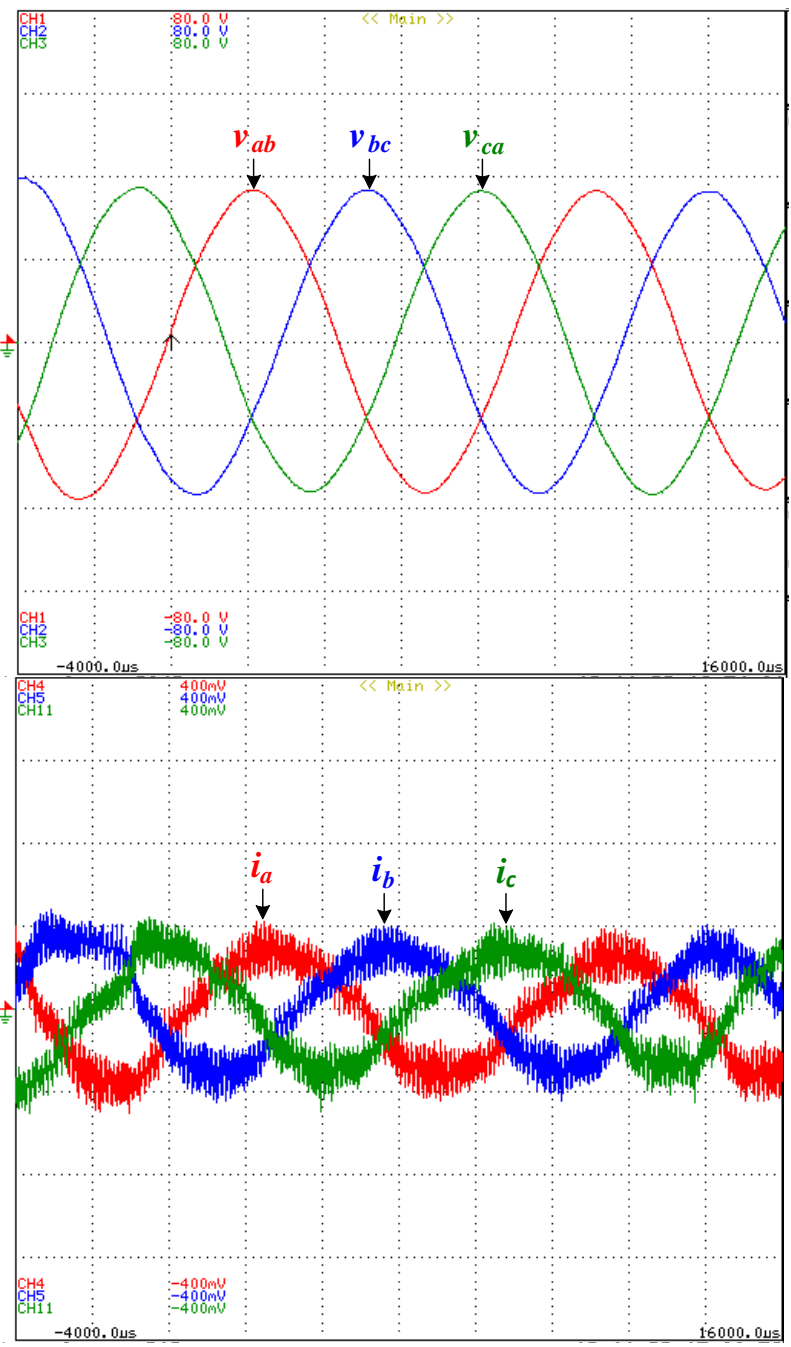

Fig. 14. Motor voltages and currents at speed of $44 \mathrm{rad} / \mathrm{s}$ without mechanical load: (a) vab, vbc and vca (20 V/div); (b) ia, ib and ic (10 A/div). 


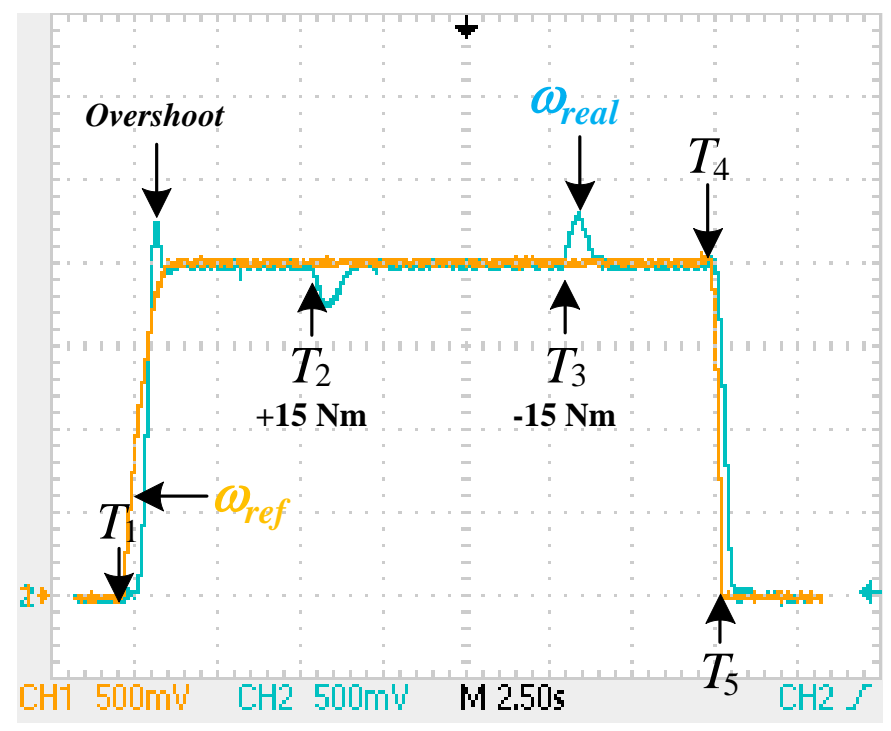

Fig. 15. Motor speed $\left(\omega_{\text {real }}-8 \mathrm{rad} / \mathrm{s} / \mathrm{div}\right)$ and its reference $\left(\omega_{\text {ref }}-8 \mathrm{rad} / \mathrm{s} / \mathrm{div}\right)$ for different mechanical loads.

(a)

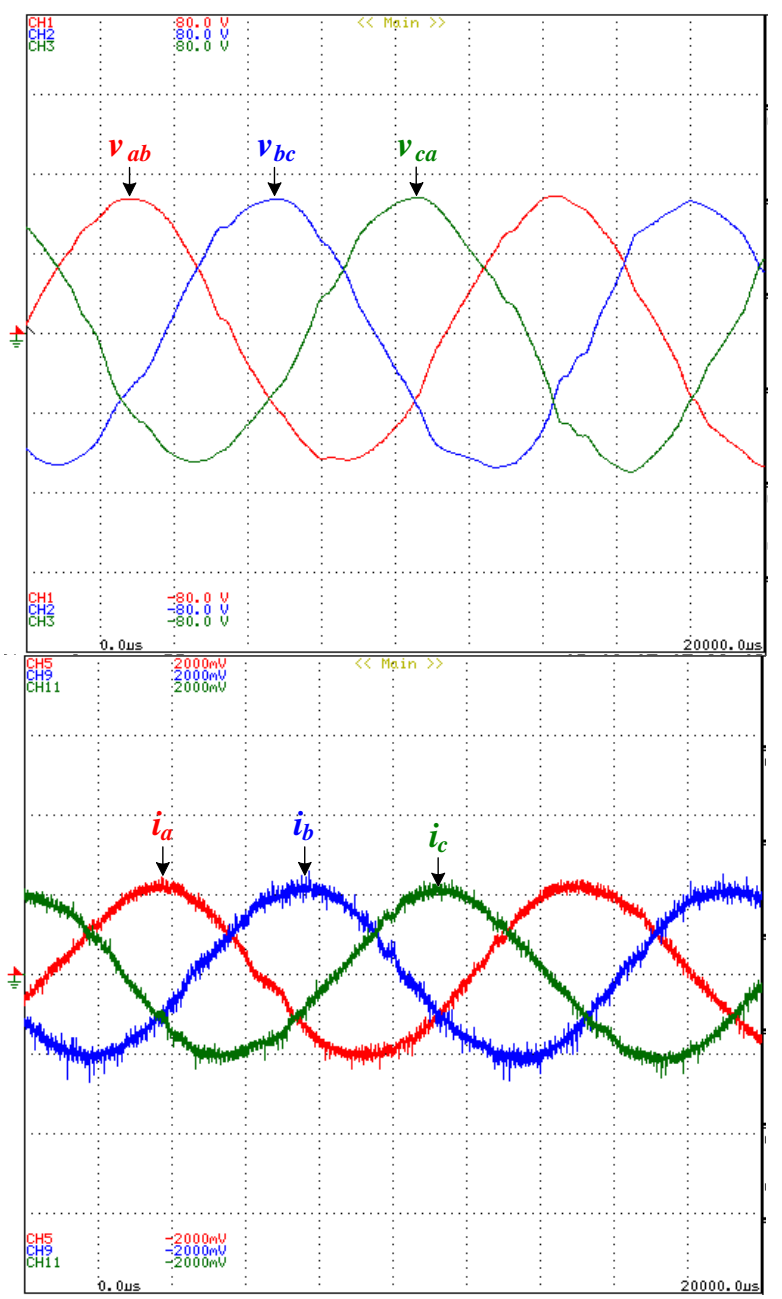

Fig. 16. Motor voltages and currents at $33 \mathrm{rad} / \mathrm{s}$ with nominal mechanical load: (a) $v_{a b}, v_{b c}$ and $v_{c a}(20 \mathrm{~V} / \mathrm{div})$; (b) $i_{a}, i_{b}$ and $i_{c}(50 \mathrm{~A} / \mathrm{div})$.
Vector Modulation (SVM). The experimental results showed that the FOC presents a good performance and fast response to speed reference variations in both no-load and load conditions.

The control platform used to implement the control system was a Spartan-3E FPGA Starter Kit Board from Xilinx. The code was programmed using Verilog language, in order to be achieved a faster system response. Currently the FPGA is already programmed in order to reduce the number of resources used. Even though, as future work it is intended to optimize the parallelization of the tasks, so that the resources consumption can be even more reduced.

\section{ACKNOWLEDGMENT}

This work has been supported by FCT - Fundação para a Ciência e Tecnologia in the scope of the project: Pest-OE/EEI/UI0319/2014.

\section{REFERENCES}

[1] J. Dixon, "Energy storage for electric vehicles," International Conference on Industrial Technology, pp. 20-26, 2010.

[2] A. Khaligh and Z. Li, "Battery, Ultracapacitor, Fuel Cell, and Hybrid Energy Storage Systems for Electric , Hybrid Electric , Fuel Cell , and Plug-In Hybrid Electric Vehicles : State of the Art," IEEE Transactions on Vehicular Technology, vol. 59, pp. 2806-2814, 2010.

[3] T. Sá, "Traction Control in Electric Vehicles," 2012.

[4] X. T. Garcia, B. Zigmund, A. Terlizzi, R. Pavlanin, and L. Salvatore, "Comparison between FOC and DTC Strategies for Permanent Magnet Synchronous Motors," Advances in Electrical and Electronic Engineering, pp. 76-81, 2012.

[5] J. Khodabakhsh, "DTC in Contrast to FOC on Power train of Hybrid Electrical Vehicle," International Conference on Electrical and Electronics Engineering, pp. 2-5, 2012.

[6] K. H. Harib, E. A. Khousa, and A. Ismail, "Field Oriented Motion Control of a 3-Phase Permanent Magnet Synchronous Motor," International Conference on Electric Power and Energy Conversion Systems, pp. 1-7, 2011.

[7] A. El Shahat and H. El Shewy, "Permanent magnet synchronous motor dynamic modeling with genetic algorithm performance improvement,' International Journal of Engineering, Science and Technology, pp. 93-106, 2010 .

[8] K. V. Kumar, P. A. Michael, J. P. John, and S. S. Kumar, "Simulation And Comparison of SPWM and SVPWM Control for Three Phase Inverter," ARPN Journal of Engineering and Applied Sciences, vol. 5, pp. 61-74, 2010.

[9] T. Wiangtong, W. Sangchai, and P. Lumyong, "FPGA based-IC design for inverter with vector modulation technique," IEEE Internationa Symposium on Circuits and Systems, vol. 1, pp. 499-502, 2000.

[10] H. Zhu, P. Dai, X. Fu, and W. Zong, "FPGA Based Embedded Implemen of Space Vector Pulse Width Modulation," Asia Pacific Conference on Postgraduate Research in Microelectronics and Electronics, pp. 5-8, 2010.

[11] D. Pedrosa, H. Gonçalves, B. Exposto, J. S. Martins, and J. L. Afonso, “A Simplified Methodology for Parameters Measurement of an Axial Flux Permanent Magnet Motor Without Neutral Point," IECON'2012 -38th Annual Conference of the IEEE Industrial Electronics Society, Montreal, Canada, pp. 1637-1642, October 2012.

[12] Xilinx, "Spartan-3E FPGA Starter Kit Board User Guide,” 2011.

[13] Delfim Pedrosa, Rui Pereira, Henrique Gonçalves, Bruno Exposto, Vítor Monteiro, J. G. Pinto, and João L. Afonso, "Development of a Digital Controller with Data Acquisition to a Test Bench for Eletric Motors," SAAEI'12 - Seminário Anual de Automação, Eletrónica Industrial e Instrumentação 2012, Guimarães, Portugal, pp. 458-463, July 2012. 
Delfim Pedrosa (S'10) was born in Leiria, Portugal on July, 1986. He is a $\mathrm{PhD}$ student at Centro Algoritmi of University of Minho. He received the M.Sc. in Industrial Electronics and Computers Engineering, from the School of Engineering of the University of Minho, in 2010. Since 2010, he is a member of the Group of Energy and Power Electronics (GEPE) at Centro Algoritmi, University of Minho, Guimarães, Portugal. His main researching interests are in Industrial Electronics and Electrical Vehicles.

Hugo Peixoto (S'13) was born in Póvoa de Lanhoso, Portugal, in 1990. He received the M.Sc. in Industrial Electronics and Computers Engineering, from the School of Engineering of the University of Minho, in 2013. Since 2014, he has been a researcher with the Laboratory of Automatic and Systems at IPN (Instituto Pedro Nunes), Coimbra, Portugal. His research interests are Power Electronics and Embedded Systems.

Henrique Gonçalves (S'02-M'10) was born in Valongo, Portugal, in 1975. He received the B.E.E. degree from Instituto Superior de Engenharia do Porto, Porto, Portugal, in 1996 and the B.S., M.Sc., and Ph.D. degrees in electrical and computer engineering from the University of Porto in 1998, 2001, and 2008, respectively. From 1999 to 2006, he was an Assistant Lecturer with the Department of Electrical Engineering, Polytechnic Institute of Bragança, Bragança, Portugal. Since 2009, he has been an Assistant Researcher with the Group of Energy and Power Electronics (GEPE) at Centro Algoritmi, University of Minho, Guimarães, Portugal. His research interests include the development of power electronics for electric vehicles and power generation using renewable energy.

Júlio S. Martins (S'79-M'93) was born in Mozambique, in 1957. He received the B.Sc. in in Electrical Engineering from the Oporto University - Portugal in 1979, and the Ph.D. degree in Systems and Informatics Engineering from the University of Minho - Portugal, in 1993. Since 1993, he has been with the Department of Industrial Electronics, University of Minho, where he is Associate Professor. He teaches Electrical Basic Electronics, Power Electronics, and Electric Machines. He is a researcher with the Group of Energy and Power Electronics (GEPE) of the Centro Algoritmi, University of Minho. His main research interests include the control of induction and synchronous motor drives and power electronics applications for the utility grid.

Carlos Couto (M'81) was born in Mozambique in 1950. He received the B.Sc. degree in Electrical Engineering from the University of Lourenzo Marques (now Maputo), Mozambique, in 1972, and the M.Sc. on Power Electronics and Systems and the $\mathrm{PhD}$ on Electrical Engineering from UMIST, Manchester, U.K., in 1979 and 1981 respectively. From 1972 to 1976 he was a lecturer with the University of Lourenzo Marques and from 1976 until today he is with the University of Minho, Guimarães, Portugal. Since 1995 he became Full Professor in the Department of Industrial Electronics, department he founded on
1989, where he has served several times as head of department. On November 2010 he took retirement of his professorship being since October 2013 University of Minho Emeritus Professor. His fields of interest are Power Electronics, Microsystems, Instrumentation and Automation. He has published more than 200 papers in technical journals and conference proceedings. Dr. Couto has been active in IEEE Industrial Electronics Society where he has served as Newsletter Chief Editor, Vice-President for Conferences, VicePresident for Technical Activities. He has been active organizing scientific events having been General Chair and Program Chair for several international conferences, namely ISIE97, ISIE2003, IECON2009. Currently he is senior AdCom member.

João Luiz Afonso (M'00) was born in Rio de Janeiro, Brazil, in 1963. He received the B.S. and M.Sc. degrees in Electrical Engineering from the Federal University of Rio de Janeiro in 1986 and 1991, respectively, and the Ph.D. degree in Industrial Electronics from the University of Minho, Guimarães, Portugal, in 2000. Since 1993, he has been with the Department of Industrial Electronics, University of Minho, where he is Associate Professor. He teaches Electrical Machines, Electrical Energy Systems, Complements of Power Electronics, Electrical Power Quality, Active Power Filters and Renewable Energy. He is a researcher with the Group of Energy and Power Electronics (GEPE), and he coordinates the thematic strand of Sustainable and Smart Cities of the Centro Algoritmi. His research interests include: Power Quality, Active Power Filters, Renewable Energy, Electric Vehicles, Energy Efficiency, Energy Storage Systems, Smart Grids and Smart Cities. 